Article

\title{
The Use of Umbelliferone in the Synthesis of New Heterocyclic Compounds
}

\author{
Ahmed A. Al-Amiery ${ }^{1,2, *}$, Ahmed Y. Musa ${ }^{1}$, Abdul Amir H. Kadhum ${ }^{1}$ and \\ Abu Bakar Mohamad ${ }^{1}$ \\ 1 Department of Chemical and Processing Engineering, Faculty of Engineering and Built \\ Environment, University of Kebangsaan Malaysia, Bangi, Selangor 43600, Malaysia \\ 2 Biotechnology Division, Applied Science Department, University of Technology, \\ Baghdad 10066, Iraq \\ * Author to whom the correspondence should be addressed; E-Mail: dr.ahmed@eng.ukm.my or \\ dr.ahmed1975@gmail.com.
}

Received: 11 July 2011; in revised form: 22 July 2011 / Accepted: 1 August 2011 / Published: 10 August 2011

\begin{abstract}
New coumarin derivatives, namely 7-[(5-amino-1,3,4-thiadiazol-2-yl)methoxy]2H-chromen-2-one (4), 5-[(2-oxo-2H-chromen-7-yloxy)methyl]-1,3,4-thiadiazol-2(3H)one (5), 2-[2-(2-oxo-2H-chromen-7-yloxy)acetyl]-N-phenylhydrazinecarbothioamide (7), 7-[(5-(phenylamino)-1,3,4-thiadiazol-2-yl)methoxy]-2H-chromen-2-one (8) and 7-[(5mercapto-4-phenyl-4H-1,2,4-triazol-3-yl)methoxy]-2H-chromen-2-one (9) were prepared starting from the natural compound umbelliferone (1). The newly synthesized compounds were characterized by elemental analysis and spectral studies (IR, ${ }^{1} \mathrm{H}-\mathrm{NMR}$ and $\left.{ }^{13} \mathrm{C}-\mathrm{NMR}\right)$.
\end{abstract}

Keywords: coumarin; ethyl bromoacetate; phosphorous oxychloride; 1,3,4-thiadiazole; thiosemicarbazide; umbelliferone

\section{Introduction}

Lactones constitute a large and diverse group of biologically active plant chemicals that have been identified in several plant families [1-3]. Coumarin and its derivatives represent one of the most active classes of compounds, possessing a wide spectrum of biological activity [4-7]. Many of these compounds have proved to be active as antibacterial [8,9], antifungal [10], anti-inflammatory [11], 
anticoagulant [12], anti-HIV [13] and antitumor [14] agents. Coumarins also have superior thermal stability and outstanding optical properties, including an extended spectral response, high quantum yields and superior photostability. Optical applications of these compounds, such as laser dyes, nonlinear optical chromophores, fluorescent whiteners, fluorescent probes, polymer science, optical recording and solar energy collectors, have been widely investigated [15-19]. The chemistry of thiosemicarbazones has received considerable attention because of their variable bonding modes, promising biological implications, structural diversity, and ion-sensing ability [20-22]. Thiazolidinones substituted in the 2-position, its derivatives and analogues exhibit unusually high in vitro activity against Mycobacterium tuberculosis [23-25]. In the current study we aimed to synthesize some new coumarins derived from umbelliferone (7-hydroxycoumarin) and thiazoles, with predictable biological activities. The chemical structures of the synthesized compounds were proven by IR, NMR spectra and elemental analysis data.

\section{Results and Discussion}

\subsection{Chemistry}

For the synthesis of new umbelliferone derivatives, the reaction sequences outlined in Schemes 1 and 2 were followed. We started from umbelliferone (1) which is commercially available or, alternatively, readily accessible through a Pechmann and Perkin condensation [26]. Synthesis of ethyl 2-(2-oxo-2H-chromen-7-yloxy) acetate (2) was brought about by refluxing ethyl bromoacetate with umbelliferone in the presence of anhydrous $\mathrm{K}_{2} \mathrm{CO}_{3}$ in dry acetone. Reaction of compound 2 with sodium hydroxide yield compound 2-(2-oxo-2H-chromen-7-yloxy)acetic acid (3) that was cyclized with thiosemicarbazide in the presence of phosphorous oxychloride to yield 7-[(5-amino-1,3,4thiadiazol-2-yl)methoxy]-2H-chromen-2-one (4) that was converted into compound $\mathbf{5}$ by adding sodium nitrate and hydrochloric acid.

Scheme 1. Synthesis of compounds 2-5.

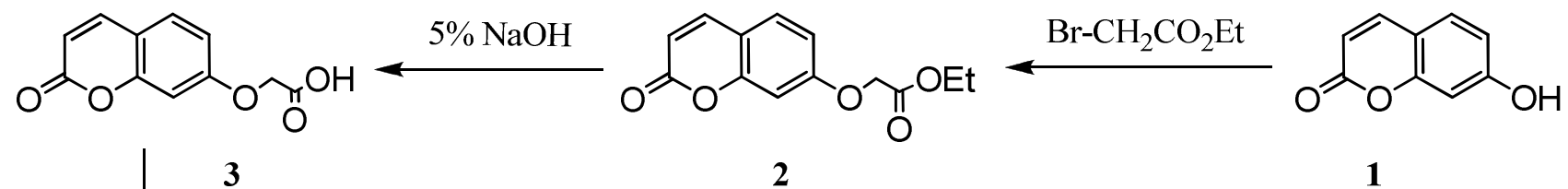

Thiosemicarbazide

$\mathrm{POCl}_{3}$

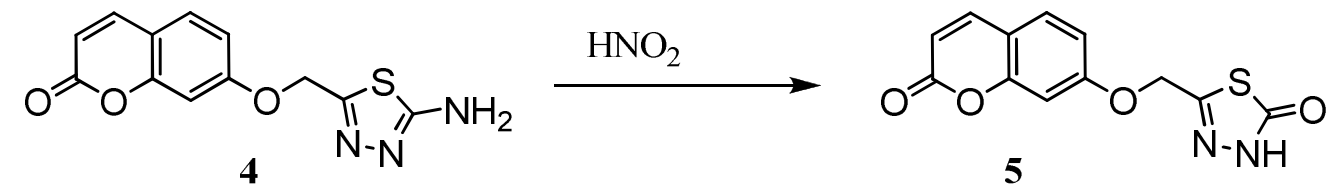


Scheme 2. Synthesis of compounds 6-9.

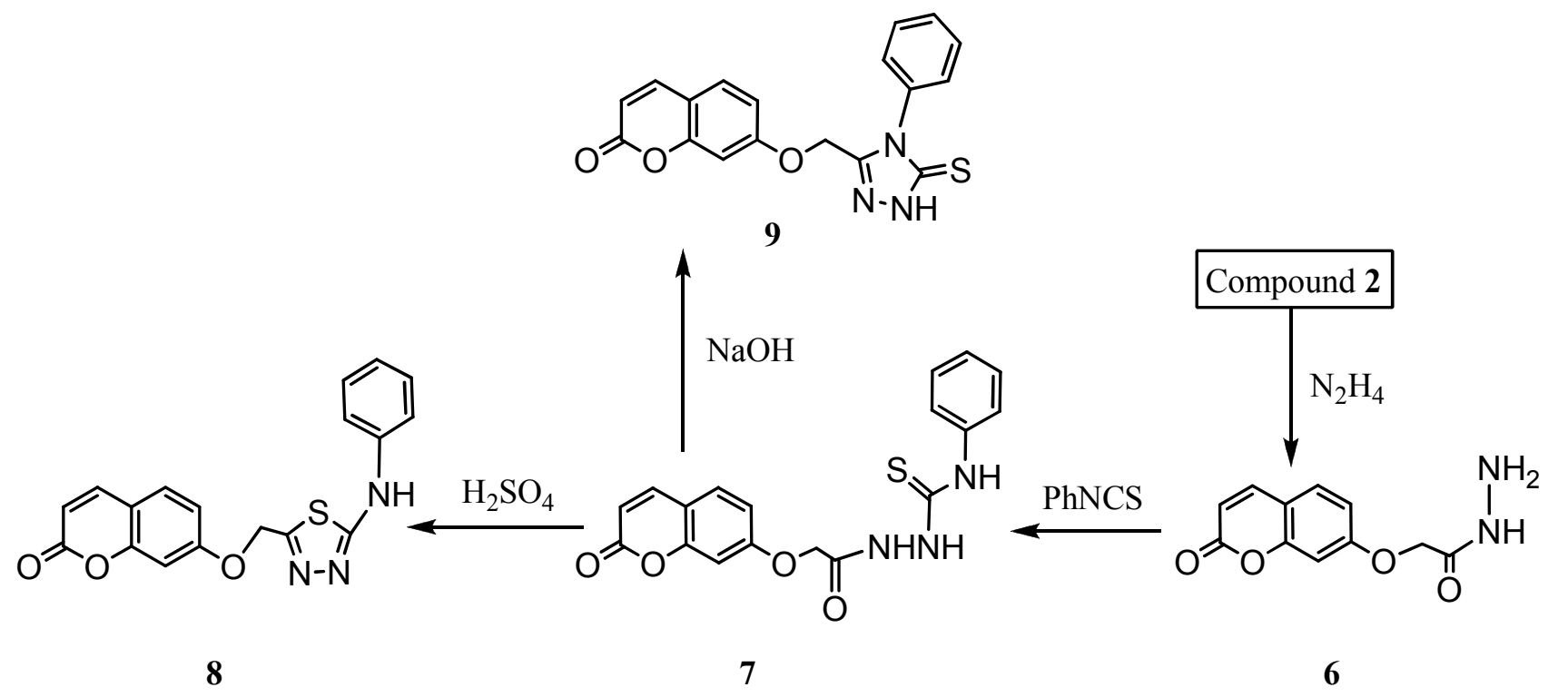

The addition of hydrazine to compound $\mathbf{2}$ yield compound $\mathbf{6}$ that was converted to compound $\mathbf{7}$ by addition of phenyl isothiocyanate. The cyclization of compound 7 by sulphuric acid yielded compound $\mathbf{8}$, while reaction with sodium hydroxide produced compound $\mathbf{9}$.

In the IR spectrum of ethyl 2-(2-oxo-2H-chromen-7-yloxy)acetate (2) the lactone carbonyl stretching frequency was observed at $1759 \mathrm{~cm}^{-1}$, whereas the ester carbonyl stretching appeared at $1717 \mathrm{~cm}^{-1}$, and a C-H aliphatic stretching frequency appeared at $2987 \mathrm{~cm}^{-1}$ that was not seen in the IR spectrum of the starting material umbelliferone, in addition of the disappearance of the hydroxyl group. In the ${ }^{1} \mathrm{H}-\mathrm{NMR}$ spectrum of compound 2, a $3 \mathrm{H}$ triplet was observed at $3.126 \mathrm{ppm}$ due to the ester $\mathrm{CH}_{3}$ protons and a quartet at $3.81 \mathrm{ppm}$ due to the ester $\mathrm{CH}_{2}$ protons. The isolated $\mathrm{CH}_{2}$ protons were observed downfield as a singlet $(2 \mathrm{H})$ at $4.770 \mathrm{ppm}$ and triplet $(2 \mathrm{H})$ at 5.260, 5.239 and 5.27. The coumarin alkene $\mathrm{C}-\mathrm{H}$ appeared at $5.416 \mathrm{ppm}$. The protons of the aromatic ring were observed as quartet $\left(7.472,7.457,7.413,7.216 \mathrm{ppm}\right.$ for $\left.\mathrm{C}_{6}-\mathrm{H}\right)$, quintet $(7.5657 .543,7.537,7.525,7.519 \mathrm{ppm}$ for $\mathrm{C}_{5}-\mathrm{H}$ ) and doublet, $7.895 \mathrm{ppm}, 7.871 \mathrm{ppm}$ for $\mathrm{C} 8-\mathrm{H}$. The ${ }^{13} \mathrm{C}-\mathrm{NMR}$ spectrum analysis for compound 2 , combined with the information from ${ }^{1} \mathrm{H}-\mathrm{NMR}$ experiments, can be considered enough to guide future synthetic work.

In the IR spectrum of 2-(2-oxo-2H-chromen-7-yloxy)acetic acid (3) the lactone carbonyl stretching frequency was observed at $1755 \mathrm{~cm}^{-1}$, whereas the carboxylic acid carbonyl stretching appeared at $1724 \mathrm{~cm}^{-1}$, and the hydroxyl group appeared as a broad band at $2975-3170 \mathrm{~cm}^{-1}$. In the ${ }^{1} \mathrm{H}-\mathrm{NMR}$ spectrum, the $\mathrm{CH}_{2}$ protons were observed downfield as a singlet $(2 \mathrm{H})$ at $4.83 \mathrm{ppm}$, and triplet $(2 \mathrm{H})$ at 5.311, 5.3 and 5.28. The $\mathrm{C}-\mathrm{H}$ (alkene) of coumarin appeared at $5.418 \mathrm{ppm}$. The protons of the aromatic ring were observed as quartet $\left(7.47,7.455,7.411,7.207 \mathrm{ppm}\right.$ for $\left.\mathrm{C}_{6}-\mathrm{H}\right)$, triplet $(7.5557 .531,7.527$ ppm for $\mathrm{C} 5-\mathrm{H})$ and doublet $(7.90 \mathrm{ppm}, 7.876 \mathrm{ppm})$ for $\mathrm{C} 8-\mathrm{H}$. The ${ }^{13} \mathrm{C}-\mathrm{NMR}$ spectrum analysis for compound 3, combined with the information from ${ }^{1} \mathrm{H}-\mathrm{NMR}$ experiments, can be considered enough to prove the structure of compound $\mathbf{3}$.

The IR spectrum is good evidence for formation of compound 4. The absence of a hydroxyl group at $2975-3170 \mathrm{~cm}^{-1}$, and appearance of a new band at 3302 and $3343 \mathrm{~cm}^{-1}$, and a lactone carbonyl 
stretching frequency at $1749 \mathrm{~cm}^{-1}$ were observed. In the ${ }^{1} \mathrm{H}-\mathrm{NMR}$ spectrum, a singlet (thiadiazole$\mathrm{NH}_{2}$ ) at $4.94 \mathrm{ppm}$ and the $\mathrm{C}-\mathrm{H}$ (alkene) of the coumarin appeared at $5.76 \mathrm{ppm}$ and 5.891. The protons of the aromatic ring were observed as multiplet (7.51-7.28). In the ${ }^{13} \mathrm{C}-\mathrm{NMR}, 163.5$ and 176.4 were new and due to the heterocyclic ring carbons.

The IR spectrum of compound 5 showed a carbonyl group at $1713 \mathrm{~cm}^{-1}$, in addition to an amino group at $3297 \mathrm{~cm}^{-1}$. In the ${ }^{1} \mathrm{H}-\mathrm{NMR}$; the coumarin $\mathrm{C}-\mathrm{H}$ (alkene) protons appeared at $5.81 \mathrm{ppm}$ (singlet) and $6.43 \mathrm{ppm}$ (singlet) and the singlet $(\mathrm{NH})$ at $5.31 \mathrm{ppm}$. In the ${ }^{13} \mathrm{C}-\mathrm{NMR}$ the thiadiazole ring carbonyl carbon atom appears at very low field (171.2).

Hydrazinolysis of compound $\mathbf{2}$ with hydrazine hydrate afforded 2-(2-oxo-2H-chromen-7yloxy)acetohydrazide (6) in good yield. The IR spectra of compound $\mathbf{6}$ showed absorption bands in the $3351.3,3287.1 \mathrm{~cm}^{-1}$ region (hydrazide $\mathrm{NH}-\mathrm{NH}_{2}$ ), $1689.2 \mathrm{~cm}^{-1}$ (amide-C=O carbonyl stretching), and $1761.5 \mathrm{~cm}^{-1}$ (lactone- $\mathrm{C}=\mathrm{O}$ carbonyl stretching). The ${ }^{1} \mathrm{H}-\mathrm{NMR}$ spectrum exhibited a singlet due to the -CO-NH-NH 2 proton at $\delta 7.93 \mathrm{ppm}$. For compound 7, the IR spectrum has the following characteristic absorption bands: $v_{\mathrm{N}-\mathrm{H}}\left(3367.6,3301.2,3278.9 \mathrm{~cm}^{-1}\right) ; v_{\mathrm{C}=\mathrm{O}}$ (1763 lactone; 1692.7 amide carbonyl $\left.\mathrm{cm}^{-1}\right), v_{\mathrm{C}=\mathrm{S}}\left(1258.5 \mathrm{~cm}^{-1}\right)$. In the IR spectrum of compound $\mathbf{8}$, no absorption band at $1692.7 \mathrm{~cm}^{-1}$ was detected, indicating the absence of the amide carbonyl group, which is evidence for the conversion of compound $\mathbf{7}$ to compound $\mathbf{8}$. Also, in the IR spectrum of the new heterocyclic compound $\mathbf{8}$ a stretching band characteristic of the $\mathrm{C}=\mathrm{N}$ group from the thiadiazole nucleus appeared at $1620.6 \mathrm{~cm}^{-1}$. Although two types of tautomers, thione or thiole, could be expected from the cyclization of compound 7, under basic conditions, only the thione type compound $\mathbf{9}$ was observed. The existence of the thione form predominantly in the solid state is demonstrated by the presence of two absorption bands at $1257 \mathrm{~cm}^{-1}$ and $3389.3 \mathrm{~cm}^{-1}$ belonging to the $v_{\mathrm{C}=\mathrm{S}}$ and $v_{\mathrm{NH}}$ groups, respectively, and by absence of $v_{\mathrm{SH}}$. In the ${ }^{13} \mathrm{C}$-NMR spectra of new heterocyclic compounds $\mathbf{8}$ and $\mathbf{9}$ the absence of the signals for the ester carbonyl and the absence of a thiocarbonyl carbon in compound $\mathbf{8}$, confirmed that cyclization of compound 7 took place. In compound 9 the signal at $168.4 \mathrm{ppm}$ indicated that in solution this compound exists predominantly in the thione tautomeric form (Scheme 3).

Scheme 3. Tautomerization of thione.
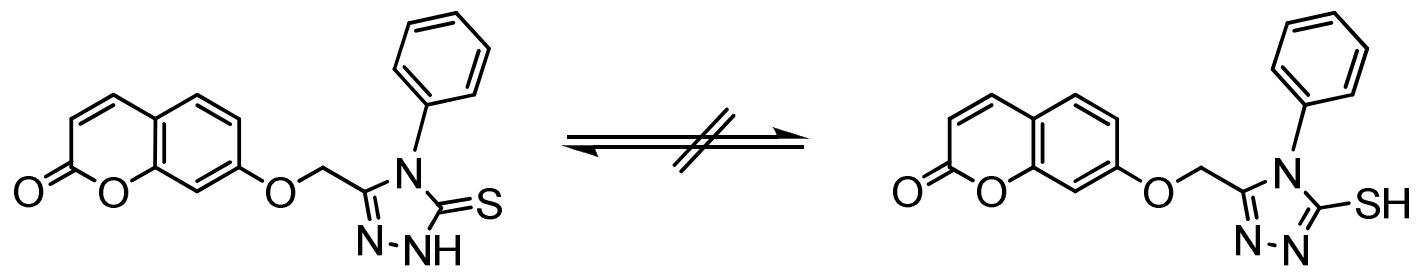

\subsection{Computational Studies}

\subsubsection{Atomic Charges and Stabilities}

The theoretical studies for compound 5 revealed that the atomic charges have been affected by the presence of the ring substituent. The minimized geometry is shown in Figure 1, where the calculated atomic charges for the compound are also indicated. It can be seen from Figure 1 that the highest atomic charge is at $[\mathrm{O}(6)-0.272)]$ the next charge value is at $[\mathrm{O}(19)-0.265]$. These results clearly indicated that these two atoms are the most reactive sites toward the reactions and bonding with the 
metals. The calculated bond and twist angles (supplementary file) and 3d-geometrical structure, indicated that this molecule is not planar.

Figure 1. 3d-geometrical structure for compound 5.

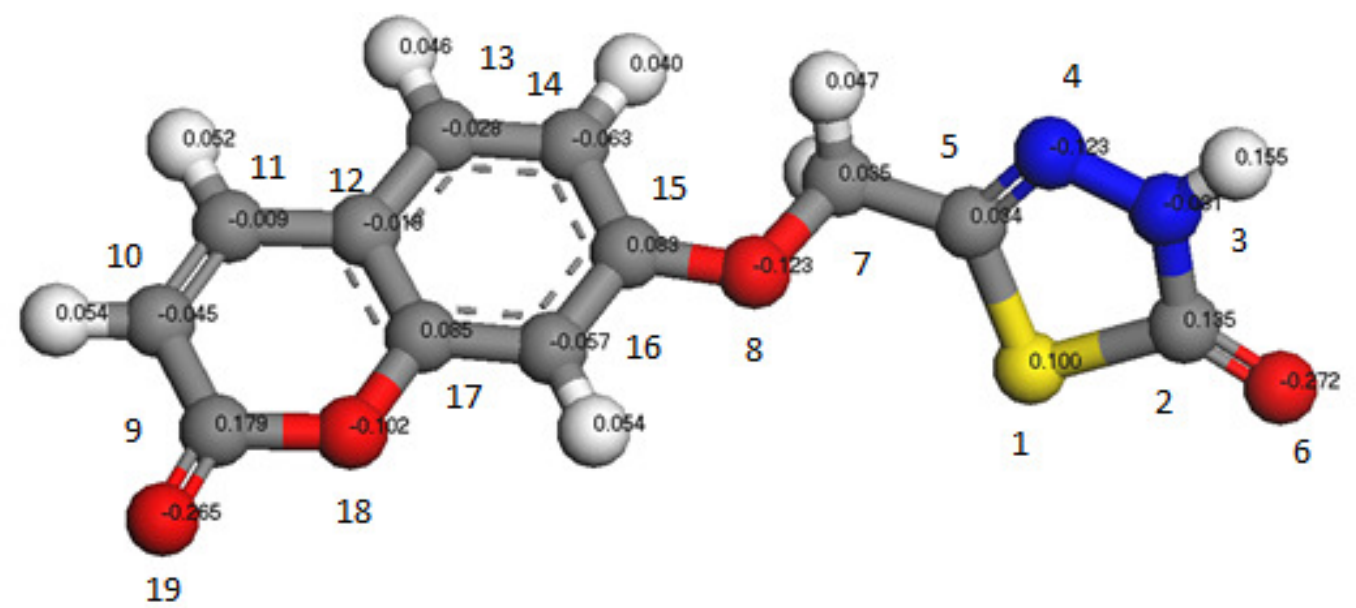

The minimized geometry for the compound $\mathbf{8}$ is shown in Figure 2. The calculated atomic charges for the compound are shown in the figure too. The results showed that the highest atomic charge is at $[\mathrm{O}(6)-0.272)]$ and the next charge value is at $[\mathrm{O}(19)-0.265]$. These results showed clearly that these two atoms are the most reactive sites toward the reactions and bonding with the metals. The determined bond angles, twist angles and 3d-geometrical structure, indicate that this molecule is not planar and the $\mathrm{C}(2)-\mathrm{C}(3)$ stereochemistry is $(Z)$.

Figure 2. 3d-geometrical structure for the compound $\mathbf{8}$.

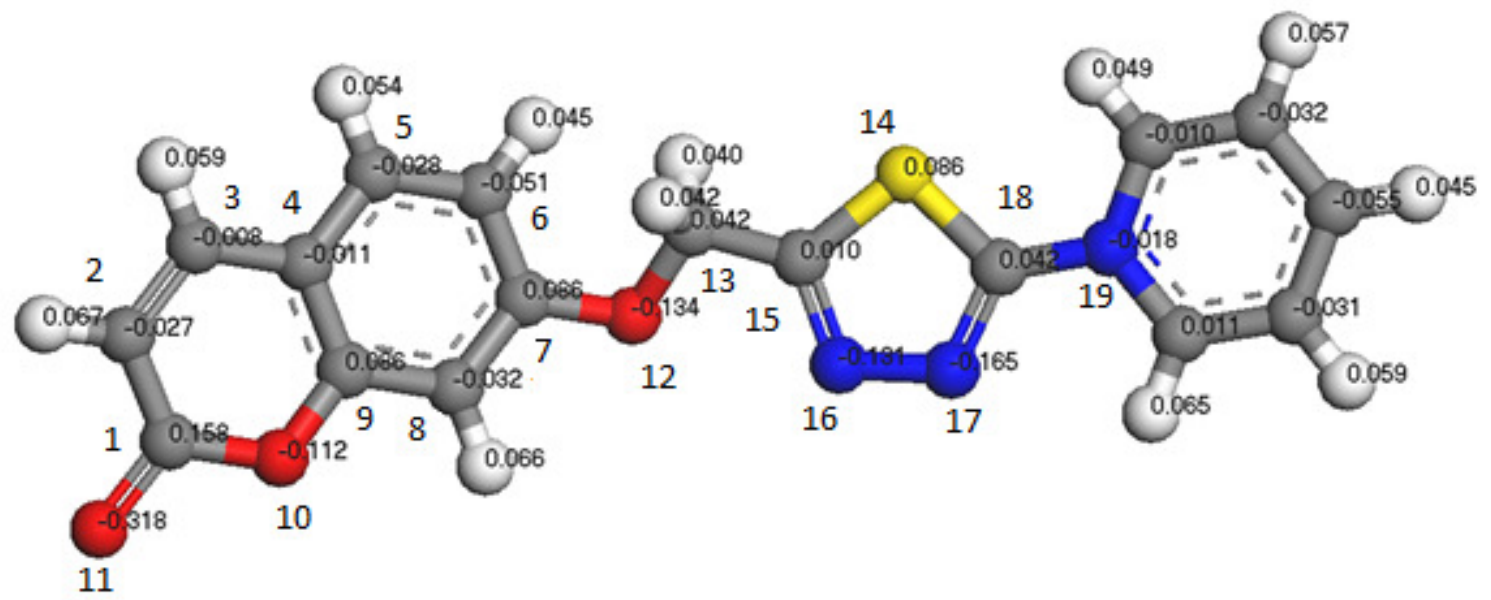

\subsubsection{Density Function Theory (DFT)}

DFT calculations were performed for compounds $\mathbf{5}$ and $\mathbf{8}$. Optimized molecular structures of the most stable forms are shown in Figure 3. Their calculated energies and relative energies are presented in Table 1. Molecular orbital calculations provide a detailed description of orbitals including spatial characteristics, nodal patterns and individual atom contributions. The contour plots of the frontier orbitals for the ground state of $\mathbf{5}$ and $\mathbf{8}$ are shown in Figure 4, including the Highest Occupied 
Molecular Orbital (HOMO) and the Lowest Unoccupied Molecular Orbital (LUMO). It is interesting to see that both orbitals are substantially distributed over the conjugation plane. It can be seen from the Figure 4 that the HOMO orbitals are located on the substituted molecule while LUMO orbitals resemble those obtained for the unsubstituted molecule and therefore the substitution has an influence on the electron donation ability, but only a small impact on electron acceptance ability [27]. The orbital energy levels of HOMO and LUMO of compounds $\mathbf{5}$ and $\mathbf{8}$ are listed in Table 2. It can be seen that the energy gaps between HOMO and LUMO is about 0.11 and 0.008 H.a. for the compounds 5 and $\mathbf{8}$, respectively. The lower value in the HOMO and LUMO energy gap explain the eventual charge transfer interaction taking place within the molecules. The dipole moments of compounds $\mathbf{5}$ and $\mathbf{8}$, were also calculated and listed in Table 3. The dipole moment for compounds $\mathbf{5}$ is oriented inwards, while the dipole moment for compounds $\mathbf{8}$, is oriented outwards.

Figure 3. Optimized molecular structures of $\mathbf{5}$ and $\mathbf{8}$ by DFT.
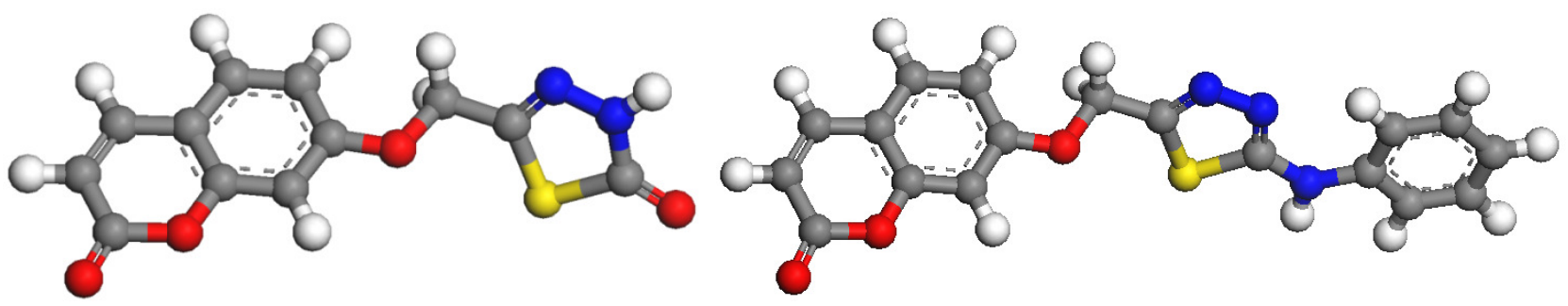

Figure 4. HOMO orbitals of 5 and $\mathbf{8}$.
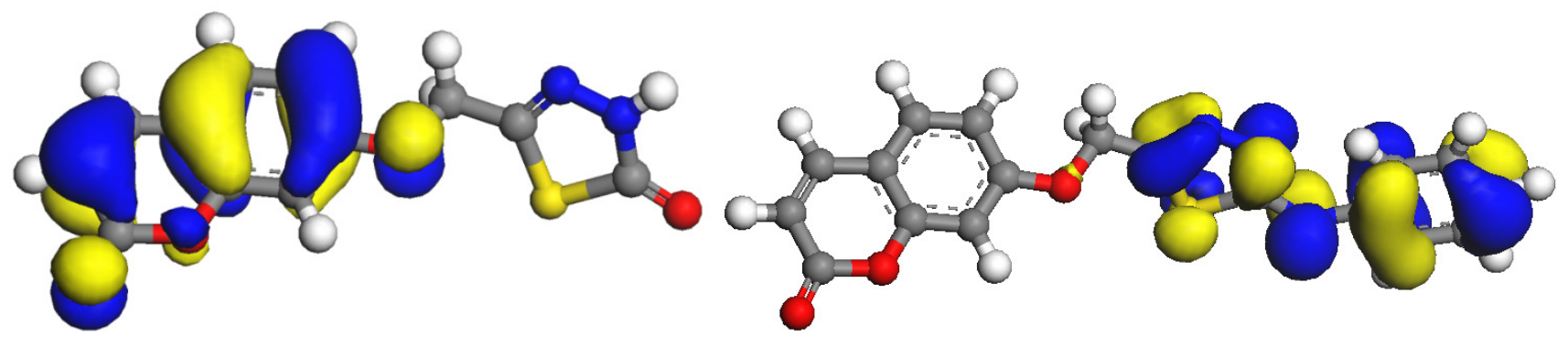

Figure 5. LUMO orbitals of $\mathbf{5}$ and $\mathbf{8 .}$

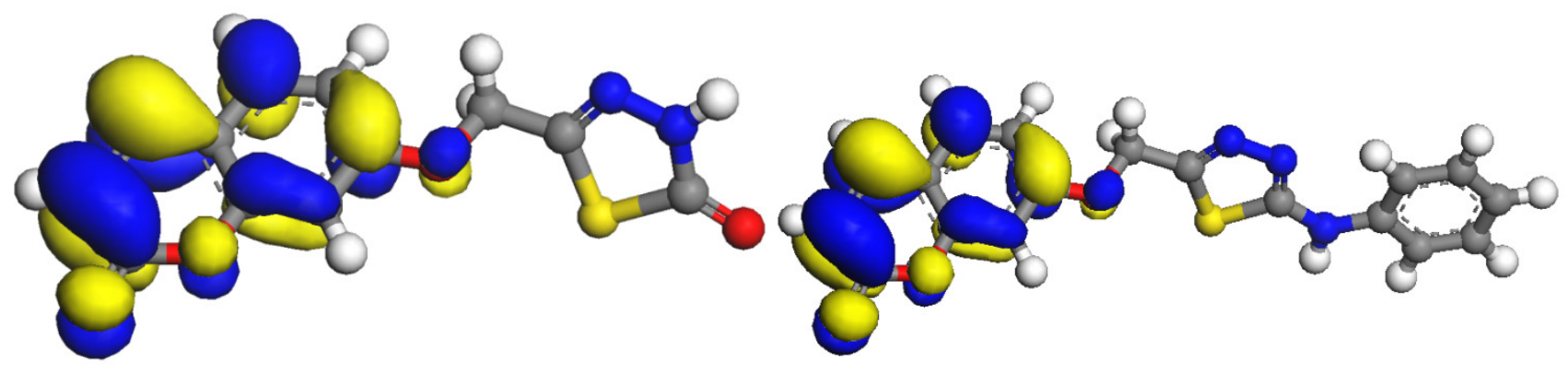

Table 1. Total Energy, relative energies and heat of formation (H.a.) for $\mathbf{5}$ and $\mathbf{8}$.

\begin{tabular}{cccccc}
\hline & $\begin{array}{c}\text { Total } \\
\text { energy }\end{array}$ & $\begin{array}{c}\text { Sum of atomic } \\
\text { energies }\end{array}$ & Kinetic & Electrostatic & $\begin{array}{c}\text { Binding } \\
\text { energy }\end{array}$ \\
\hline 5 & -120.394 & -1265.697 & -11.406 & 2.934 & -5.061 \\
8 & -145.743 & -1474.474 & -11.317 & -0.569 & -7.135 \\
\hline
\end{tabular}


Table 2. HOMO and LUMO energies of 5 and $\mathbf{8}$.

\begin{tabular}{cccc}
\hline & HOMO (H. a) & LUMO (H. a) & $\Delta \mathbf{E}$ \\
\hline 5 & -0.207 & -0.097 & -0.11 \\
8 & -0.190 & -0.092 & -0.098 \\
\hline
\end{tabular}

Table 3. The dipole moments (Debye) of 5 and $\mathbf{8}$.

\begin{tabular}{ccccc}
\hline & x-component & y-component & z-component & magnitude \\
\hline 5 & -0.11 & 2.694 & 0.019 & 2.697 \\
8 & 2.016 & 4.254 & 0.627 & 4.748 \\
\hline
\end{tabular}

\section{Experimental}

\subsection{General}

The chemicals used for the synthesis were supplied by Sigma-Aldrich. Purity of the compounds was checked on thin layer chromatography (TLC) plates (Silicagel G) using the solvent systems benzene-ethyl acetate-methanol (40:30:30, v/v/v) and toluene-acetone $(75: 25, \mathrm{v} / \mathrm{v})$. The spots were located under UV light (254 and $365 \mathrm{~nm}$ ). The IR spectra were obtained on a Thermo Scientific, Nicolet 6700 FT-IR spectrometer (without $\mathrm{KBr}$ or CsI pellets). The ${ }^{1} \mathrm{H}-\mathrm{NMR}$ spectra were obtained on a Jeol jnm-ECP400 FT-NMR system. Elemental microanalysis was carried out using a model 5500-Carlo Erba C.H.N elemental analyzer instrument. A Gallenkamp M.F.B.600.010 F melting point apparatus was used to measure the melting points of all the prepared compounds.

\subsection{Synthesis}

Ethyl 2-(2-oxo-2H-chromen-7-yloxy)acetate (2). A suspension of 7- hydroxycoumarin (6.17 mmol) in acetone $(30 \mathrm{~mL})$ was refluxed with ethyl bromoacetate $(9.15 \mathrm{mmol})$ and $\mathrm{K}_{2} \mathrm{CO}_{3}(4.69 \mathrm{~g}, 33.91 \mathrm{mmol})$ for $12 \mathrm{~h}$. After cooling, the mixture was evaporated to dryness and the residue was partitioned between $\mathrm{CHCl}_{3}(50 \mathrm{~mL})$ and water $(50 \mathrm{~mL})$. The organic phase was dried $\left(\mathrm{Na}_{2} \mathrm{SO}_{4}\right)$, filtered and evaporated to dryness. The residue was recrystallized from acetone, yield $82 \%$, m.p. $112.5{ }^{\circ} \mathrm{C} ;{ }^{1} \mathrm{H}-\mathrm{NMR}\left(\mathrm{CDCl}_{3}\right): \delta$ $3.126\left(\mathrm{t}, 3 \mathrm{H}, \mathrm{CH}_{3}\right), \delta 3.81\left(\mathrm{~m}, 2 \mathrm{H}, \mathrm{CH}_{2}\right), \delta 4.77(\mathrm{~s}, 2 \mathrm{H})$ and $\delta 5.260, \delta 5.239, \delta 5.270\left(\mathrm{~s}, 2 \mathrm{H}, \mathrm{CH}_{2}\right), \delta$ $5.416(\mathrm{~s}, 1 \mathrm{H},-\mathrm{C}=\mathrm{C}-\mathrm{H}), \delta 7.472, \delta 7.457, \delta 7.413, \delta 7.216$ (q, $1 \mathrm{H}$, aromatic); ${ }^{13} \mathrm{C}-\mathrm{NMR}$ (DMSO-d 6 ): 22.3, 58.9, 65.1, 103.8, 108, 108.9, 110.1, 123.7, 154.6, 157.1, 160.8, 161.2, 166.5; IR: $2987 \mathrm{~cm}^{-1}$ (C-H, aliphatic), $1759 \mathrm{~cm}^{-1}\left(\mathrm{C}=\mathrm{O}\right.$, lactone), $1717 \mathrm{~cm}^{-1}\left(\mathrm{C}=\mathrm{O}\right.$, ester); Anal. Calcd. for $\mathrm{C}_{13} \mathrm{H}_{12} \mathrm{O}_{5}: \mathrm{C}$ $62.90 \%$, H 4.87\%. Found: C 61.81\% H $4.01 \%$.

2-(2-Oxo-2H-chromen-7-yloxy)acetic acid 3. A solution of the compound 2 (2.7 mmol) and 5\% sodium hydroxide $(2.16 \mathrm{~mL})$ in ethanol $(15 \mathrm{~mL})$ was stirred under reflux for $2 \mathrm{~h}$. After removal of the solvent, the residue was dissolved in water and acidified with $\mathrm{HCl} 6 \mathrm{M}$. The white solid collected by filtration was washed with cool water, dried and recrystallized from ethanol, yield $92 \%$, m.p. $210.5^{\circ} \mathrm{C}$; ${ }^{1} \mathrm{H}-\mathrm{NMR}\left(\mathrm{CDCl}_{3}\right): \delta 4.83(\mathrm{~s}, 2 \mathrm{H})$ and $\delta 5.311, \delta 5.300, \delta 5.280\left(\mathrm{~s}, 2 \mathrm{H}, \mathrm{CH}_{2}\right), \delta 5.418(\mathrm{~s}, 1 \mathrm{H},-\mathrm{C}=\mathrm{C}-\mathrm{H})$, $\delta 7.470, \delta 7.455, \delta 7.411, \delta 7.207\left(\mathrm{q}, 1 \mathrm{H}, \mathrm{C}_{6}-\mathrm{H}\right.$ aromatic ring), $\delta 7.555, \delta 7.531, \delta 7.527$ (t, $\left.1 \mathrm{H}\right)$ for $\mathrm{C}_{6}-\mathrm{H}$ aromatic ring, $\delta 7.90, \delta 7.876\left(\mathrm{~s}, 1 \mathrm{H}, \mathrm{C}_{8}-\mathrm{H}\right.$ aromatic ring ); ${ }^{13} \mathrm{C}-\mathrm{NMR}$ (DMSO-d $\mathrm{d}_{6}$ ): 105.2, 110.3, 
112.9, 113.9, 124.1, 153.9, 156.3, 161.2, 161.9, 167.1; IR: 3170-2975 cm (hydroxyl), $1755 \mathrm{~cm}^{-1}$ $\left(\mathrm{C}=\mathrm{O}\right.$, lactone), $1724 \mathrm{~cm}^{-1}\left(\mathrm{C}=\mathrm{O}\right.$, carboxylate); Anal. Calcd. for $\mathrm{C}_{11} \mathrm{H}_{8} \mathrm{O}_{5}: \mathrm{C} 60.00 \%, \mathrm{H} \mathrm{3.66 \%}$. Found: C $58.40 \%$ H $2.94 \%$.

7-[(5-Amino-1,3,4-thiadiazol-2-yl)methoxy]-2H-chromen-2-one (4). Phosphorus oxychloride (20 mL) was added to compound $3(0.05 \mathrm{~mol})$ and the mixture was stirred for $1 \mathrm{~h}$. at room temperature. Thiosemicarbazide (4.56 gm, $0.05 \mathrm{~mol}$ ) was added and the mixture was heated under reflux for $5 \mathrm{~h}$. On cooling, the mixture was poured on to ice. After $4 \mathrm{~h}$. the mixture was stirred for $15 \mathrm{~min}$. to decompose the excess phosphorus oxychloride, then heated under reflux for $30 \mathrm{~min}$, cooling, the mixture was neutralized by $5 \%$ potassium hydroxide, the precipitate was filtered, washed with water, dried and recrystallized from ethanol, yield 51\%, m.p. $105{ }^{\circ} \mathrm{C} ;{ }^{1} \mathrm{H}-\mathrm{NMR}\left(\mathrm{CDCl}_{3}\right): \delta 4.94\left(\mathrm{~s}, 1 \mathrm{H}, \mathrm{NH}_{2}\right), \delta 5.760$, $5.891(\mathrm{~s}, 1 \mathrm{H},-\mathrm{C}=\mathrm{C}-\mathrm{H}), \delta 7.510-7.283\left(\mathrm{~m}, 1 \mathrm{H}, \mathrm{C}-\mathrm{H}\right.$ aromatic ring); ${ }^{13} \mathrm{C}-\mathrm{NMR}$ (DMSO-d $\left.\mathrm{d}_{6}\right): 101.9$, 111.0, 113.1, 114.1, 128.1, 149.5, 156.3, 160.8, 161.2, 163.5, 168.3, 176.4; IR: 3302 and $3343 \mathrm{~cm}^{-1}$ (N-H, amine), $1747 \mathrm{~cm}^{-1}\left(\mathrm{C}=\mathrm{O}\right.$, lactone); Anal. Calcd. for $\mathrm{C}_{12} \mathrm{H}_{9} \mathrm{~N}_{3} \mathrm{O}_{3} \mathrm{~S}: \mathrm{C} 52.36 \%, \mathrm{H} 3.30 \%, \mathrm{~N}$ $15.26 \%$. Found: C $50.49 \%$ H $2.76 \%$, N $16.20 \%$.

5-[(2-Oxo-2H-chromen-7-yloxy)methyl]-1,3,4-thiadiazol-2(3H)-one (5). 10\% Aqueous sodium nitrite solution $(10 \mathrm{~mL})$ was added dropwise with continuous stirring over a period of $20 \mathrm{~min}$ to an cooled (ice-bath) suspension of compound $4(0.01 \mathrm{~mol})$ and hydrochloric acid $(5 \mathrm{~mL})$ in cold water $(20 \mathrm{~mL})$. The temperature was then allowed to rise to room temperature and the mixture was heated to boiling for $10 \mathrm{~min}$, cooled and allowed to stand overnight. The separated crude product was filtered, washed with water, dried and recrystallized from ethanol, yield $47 \%$, m.p. $133{ }^{\circ} \mathrm{C} ;{ }^{1} \mathrm{H}-\mathrm{NMR}\left(\mathrm{CDCl}_{3}\right): \delta 5.31$ $(\mathrm{s}, 1 \mathrm{H}, \mathrm{NH}), \delta 5.810,6.430(\mathrm{~s}, 1 \mathrm{H},-\mathrm{C}=\mathrm{C}-\mathrm{H}), \delta 7.811-7.299\left(\mathrm{~m}, 1 \mathrm{H}, \mathrm{C}-\mathrm{H}\right.$ aromatic ring); ${ }^{13} \mathrm{C}-\mathrm{NMR}$ (DMSO-d ${ }_{6}$ ): 103.2, 115.1, 117.5, 117.9, 123.2, 155.3, 155.9, 156.4, 160.8, 161.1, 166.2, 171.2; IR: $3397 \mathrm{~cm}^{-1}\left(\mathrm{~N}-\mathrm{H}\right.$, amine), $1713 \mathrm{~cm}^{-1}(\mathrm{C}=\mathrm{O}$, lactone $)$; Anal. Calcd. for $\mathrm{C}_{12} \mathrm{H}_{8} \mathrm{~N}_{2} \mathrm{O}_{4} \mathrm{~S}: \mathrm{C} 52.17 \%, \mathrm{H}$ $2.29 \%$, N 10.14\%. Found: C 50.34\% H 3.01\%, N 9.51\%.

2-(2-Oxo-2H-chromen-7-yloxy)acetohydrazide (6). A solution of compound 2 (10 mmol) in ethanol $(25 \mathrm{~mL})$ was refluxed with hydrazine hydrate $(25 \mathrm{mmol})$ for $4 \mathrm{~h}$. After concentrating the reaction mixture a solid mass separated out and was recrystallized from ethanol, yield 75\%, m.p. $234.5{ }^{\circ} \mathrm{C}$; ${ }^{1} \mathrm{H}-\mathrm{NMR}\left(\mathrm{CDCl}_{3}\right): \delta 7.93\left(-\mathrm{CO}-\mathrm{NHNH}_{2}\right), \delta 4.61(\mathrm{~s}, 2 \mathrm{H})$ and $\delta 5.251, \delta 5.222, \delta 5.214\left(\mathrm{~s}, 2 \mathrm{H}, \mathrm{CH}_{2}\right), \delta$ $5.716(\mathrm{~s}, 1 \mathrm{H},-\mathrm{C}=\mathrm{C}-\mathrm{H}), \delta 7.61-7.110\left(\mathrm{~s}, 1 \mathrm{H}\right.$, aromatic ring); IR: 3351.3 and $3287.1 \mathrm{~cm}^{-1}(\mathrm{~N}-\mathrm{H}$, hydrazide), $1761.5 \mathrm{~cm}^{-1}$ (C=O, lactone), $1689.2 \mathrm{~cm}^{-1}\left(\mathrm{C}=\mathrm{O}\right.$, amide); Anal. Calcd. for $\mathrm{C}_{11} \mathrm{H}_{10} \mathrm{~N}_{2} \mathrm{O}_{4}: \mathrm{C}$ $56.40 \%, \mathrm{H} 4.38 \%$, N $11.96 \%$. Found: C 54.44\%, H 4.04\%, N $10.79 \%$.

2-[2-(2-Oxo-2H-chromen-7-yloxy)acetyl]-N-phenylhydrazinecarbothioamide (7). A mixture of hydrazide $6(2 \mathrm{mmol})$ and phenyl isothiocyanate $(2 \mathrm{mmol})$ in ethanol $(15 \mathrm{~mL})$ was refluxed for $12 \mathrm{~h}$. The reaction mixture was cooled and the separated product was filtered off, dried and recrystallized from ethanol, yield 61\%, m.p. $199{ }^{\circ} \mathrm{C}$; IR: 3367.6, 3301.2 and $3278.9 \mathrm{~cm}^{-1}$ (N-H, hydrazone), $1763 \mathrm{~cm}^{-1}\left(\mathrm{C}=\mathrm{O}\right.$, lactone), $1692.7 \mathrm{~cm}^{-1}(\mathrm{C}=\mathrm{O}$, amide $), 1258.5 \mathrm{~cm}^{-1}(\mathrm{C}=\mathrm{S})$; Anal. Calcd. for $\mathrm{C}_{18} \mathrm{H}_{15} \mathrm{~N}_{3} \mathrm{O}_{4} \mathrm{~S}$ : C 58.53\%, H 4.09\%, N 11.38\%. Found: C 56.49\%, H 3.78\%, N 10.22\%. 
7-[(5-(Phenylamino)-1,3,4-thiadiazol-2-yl)methoxy]-2H-chromen-2-one (8). A mixture of compound 7 (0.15 mmol) and concentrated $\mathrm{H}_{2} \mathrm{SO}_{4}(5 \mathrm{~mL})$ was stirred in ice path for $5 \mathrm{~h}$ and then, at room temperature, for another $5 \mathrm{~h}$. The reaction mixture was neutralized with a diluted solution of ammonium hydroxide, in ice bath. The precipitated was filtered off, washed with water, dried and recrystallized from ethanol, yield 57\%, m.p. $244{ }^{\circ} \mathrm{C}$; IR: $3291 \mathrm{~cm}^{-1}(\mathrm{~N}-\mathrm{H}), 1762.8 \mathrm{~cm}^{-1}(\mathrm{C}=\mathrm{O}$, lactone), $1620.6 \mathrm{~cm}^{-1}(\mathrm{C}=\mathrm{N}) ;{ }^{13} \mathrm{C}-\mathrm{NMR}$ (DMSO-d $)_{6}$ : 100.3, 107.2, 111.9, 114.2, 122.0, 125.4, 126.2, 126.8, 129.2, 129.7, 141.6, 156.2, 156.9, 157.3, 158.1, 160.5, 169.3; Anal. Calcd. for $\mathrm{C}_{18} \mathrm{H}_{13} \mathrm{~N}_{3} \mathrm{O}_{3} \mathrm{~S}$ : C $61.53 \%, \mathrm{H} 3.73 \%$, N $11.96 \%$. Found: C $61.01 \%, \mathrm{H} 3.11 \%, \mathrm{~N} 11.32 \%$.

7-[(4-Phenyl-5-thioxo-4,5-dihydro-1H-1,2,4-triazol-3-yl)methoxy]-2H-chromen-2-one (9). Compound $7(0.5 \mathrm{mmol})$ was added to $8 \% \mathrm{NaOH}$ solution $(4 \mathrm{~mL})$ and the reaction mixture was heated under reflux for 4 hours. After cooling, the solution was acidified with a diluted solution of $\mathrm{HCl}$. The crude product was precipitated, filtered off and washed with water. The solid thus separated was dried and recrystallized from chloroform, yield $44 \%$, m.p. $251{ }^{\circ} \mathrm{C}$; IR: $3389.3 \mathrm{~cm}^{-1}(\mathrm{~N}-\mathrm{H}), 1767.7 \mathrm{~cm}^{-1}(\mathrm{C}=\mathrm{O}$, lactone), $1618.1 \mathrm{~cm}^{-1}(\mathrm{C}=\mathrm{N}), 1257 \mathrm{~cm}^{-1}(\mathrm{C}=\mathrm{S}) ;{ }^{13} \mathrm{C}-\mathrm{NMR}$ (DMSO-d 6 ): 99.6, 109.8, 112.3, 114.1, 122.3, 127.1, 129.3, 129.8, 130.1, 130.9, 134.4, 154.0, 155.8, 156.5, 157.2, 163.6, 168.4; Anal. Calcd. for $\mathrm{C}_{18} \mathrm{H}_{13} \mathrm{~N}_{3} \mathrm{O}_{3} \mathrm{~S}$ : C $61.53 \%, \mathrm{H} 3.73 \%$, N $11.96 \%$. Found: C $61.01 \%, \mathrm{H} 3.11 \%, \mathrm{~N} 11.32 \%$.

\subsection{DFT}

The molecular drawings of the nine thio compounds were plotted using Visualization Materials Studio 5.5. All quantum chemical calculations were performed using Density Functional Theory (DFT) as implemented in the Materials Studio 5.5 software. $\mathrm{DMol}^{3}$ model was employed to obtain quantum chemical parameters and to optimize the molecules' geometry. These calculations employed an $a b$ initio, generalized gradient approximation (GGA) with the Lee-Yang-Parr correlation functional (BLYP) functional and Double Numerical d-functions (DND) basis set. This approach is shown to yield favorable geometries for a wide variety of systems. The following quantum chemical indices were calculated: the energy of the highest occupied molecular orbital (HOMO), the energy of the lowest unoccupied molecular orbital (LUMO) and dipole moment.

\section{Conclusions}

In this study, the compounds 2-9 were synthesized, and characterized using various spectroscopic methods and elemental analysis. The synthesized compounds were studied theoretically and the atomic charges, heat of formation and stereochemistry were estimated, and it was found that compounds $\mathbf{5}$ and 8 are not planar.

\section{References}

1. Mirjalili, M.; Moyano, E.; Bonfill, M.; Cusido, M.; Palazón, J. Steroidal Lactones from Withania somnifera, an Ancient Plant for Novel Medicine. Molecules 2009, 14, 2373-2393.

2. Li, J.; Zhou, B. Biological Actions of Artemisinin: Insights from Medicinal Chemistry Studies. Molecules 2010, 15, 1378-1397. 
3. Al-Amiery, A.A.; Mohammed, A.; Ibrahim, H.; Abbas, A. Study the biological activities of tribulus terrestris extracts. World Acad. Sci. Eng. Technol. 2009, 57, 433-435.

4. El-Agrody, A.; Abd El-Latif, M.; El-Hady, N.; Fakery1, A.; Bedair, A. Heteroaromatization with 4-ydroxycoumarin Part II: Synthesis of Some New Pyrano[2,3-d]pyrimidines, [1,2,4]triazolo[1,5c]pyrimidines and Pyrimido[1,6-b] [1,2,4]triazine Derivatives. Molecules 2001, 6, 519-527.

5. Rositca, D.; Nikolova, G.N.; Vayssilov, R.; Bojilova, R. Stereoselective $[2+2]$ Photodimerization of 3-Substituted 2-Alkoxy-2-oxo-2H-1,2-benzoxaphosphorines. Molecules 2002, 7, 420-432.

6. Flašík, R.; Stankovičová, H.; Gáplovský, A.; Donovalová, J. Synthesis and Study of Novel Coumarin Derivatives Potentially Utilizable as Memory Media. Molecules 2009, 14, 4838-4848.

7. Sergiy, K.; Bylov, I.; Sytnik, K.; Chernykh, V.; Bilokin, Y. A New Pathway to 3-Hetaryl-2-oxo2H-chromenes: On the Proposed Mechanisms for the Reaction of 3-Carbamoyl-2iminochromenes with Dinucleophiles. Molecules 2000, 5, 1146-1165.

8. Jianwei, H.; Yong, X.; Jingwei, Z.; Shizheng, Z. 1-Proline catalyzed condensation-cyclization tandem process: Facile and effective synthesis of 3-polyfluoroalkanesulfonyl coumarin. J. Fluorine Chem. 2011, 132, 409-413.

9. Musicki, B.; Periers, P.; Laurin, D.; Ferroud, Y.; Bendetti, S.; Lachaud, F.; Chatreaux, J.; Haesslein, L.; Iltis, A.; Pierre, C.; Khider, J.; Tessot, N.; Airault, P.; Bonnefoy, A.; Vicat, P.; Klich, M. Bioorg. Med. Chem. Lett. 2000, 10, 1695-1699.

10. Bistra, S.; Voislava, J.; Boris, S.; Nikolova, P.; Goran, S.; Bozhna, M.; Emil, P. Experimental and theoretical investigation of the structure and nucleophilic properties of 4-aminocoumarin. ARKIVOC 2010, $x, 62-76$.

11. Garazd, M.M.; Muzychka, O.V.; Voyk, A.I.; Nagorichna, I.V.; Ogorodniichuk, A.S. Synthesis and antioxidant activity of 3-substituted 5,7-dihydroxy-4-methylcoumarins. Chem. Nat. Compd. 2007, 43, 19-23.

12. Edmont, V.; Jochen, M. Pechmann Reaction Promoted by Boron Trifluoride Dihydrate. Molecules 2005, 10, 762-76.

13. Kotali, A.; Lafazanis, I.; Harris, P. ChemInform Abstract: Synthesis of 6,7-Diacylcoumarins via the Transformation of a Hydroxy into a Carbonyl Group. Synth. Commun. 2008, 38, 3996-4006.

14. Nofal, Z.M.; El-Zahar, M.; Abd El-Karim, S. Novel coumarin derivatives with expected biological activity. Molecules 2000, 5, 99-113.

15. Lin, S.; Kuo, P.; Yang, D. Design and Synthesis of a Coumarin-based Acidichromic Colorant. Molecules 2007, 12, 1316-1324.

16. Verdía, P.; Santamarta, F.; Tojo, E. Knoevenagel Reaction in [MMIm][MSO $]$ : Synthesis of Coumarins. Molecules 2011, 16, 4379-4388.

17. Mukhatar, S.; Mujeebur, R.V.P.; Ansari, W.H.; Lemiere, G.; De Groot, A.; Dommisse, R. Bifunctional Derivative of p,p'-Dichlorochalcone. Part II. Synthesis of a Novel Compound 2-[2-Carboxymethylthio-2-(4-chlorophenyl)ethyl]-2-(4-chlorophenyl)-4-thiazolidinone. Molecules 1999, 4, 232-237.

18. Milan, C.; Maja, M.; Tomislav, B.; Nela, D.; Valentina, R. Design and Synthesis of Some Thiazolidin-4-ones Based on(7-Hydroxy-2-oxo-2H-chromen-4-yl) Acetic Acid. Molecules 2009, $14,2501-2513$. 
19. Butsch, W.L.; Stewart, J.D. Administration of dicoumarin compounds for prophylaxis of post operative thrombosis and embolism. Arch. Surg. 1942, 45, 551-553.

20. Casas, J.S.; García-Tasende, M.S.; Sordo, J. Corrigendum to Main group metal complexes of semicarbazones and thiosemicarbazones. A structural review. Coordin. Chem. Rev. 2000, 209, 197-261.

21. Mishra, D.; Naskar, S.; Michael, G.; Kumar, S. Synthesis, spectroscopic and redox properties of some ruthenium(II) thiosemicarbazone complexes Structural description of four of these complexes. Chattopadhyay 2006, 359, 585-592.

22. Al-Amiery, A.A.; Al-Majedy, K.; Abdulreazak H.; Abood, H. Synthesis, Characterization, Theoretical Crystal Structure and Antibacterial activities of some transition metal complexes of the thiosemicarbazone (Z)-2-(pyrrolidin-2-ylidene)hydrazinecarbothioamide. Bioinorg. Chem. Appl. 2011, 2011, Article ID 483101, 6 pages.

23. Hintz, K.K.; Ren, J. Tetramethyl pyrazine elicits disparate responses in cardiac contraction and intracellular $\mathrm{Ca}^{2+}$ transients in isolated adult rat ventricularmyocytes. Vascul. Pharmacol. 2003, 40, 213-217.

24. Cacic, M.; Trkovnik, M.; Cacic, F.; Has-Schon, E. Synthesis and Antimicrobial Activity of Some Derivatives of (7-Hydroxy-2-oxo-2H-chromen-4-yl)-acetic Acid Hydrazide. Molecules 2006, 11 , 134-147.

25. Ezabadi, I.R.; Camoutsis, C.; Zoumpoulakis, P.; Geronikaki, A.; Soković, M.; Glamocilija, J.; Cirić, A. Sulfonamide-1,2,4-triazole derivatives as antifungal and antibacterial agents: Synthesis, biological evaluation, lipophilicity, and conformational studies. Bioorg. Med. Chem. 2008, $16,1150$.

26. Kadhum, A.H.; Mohamad, A.; Al-Amiery, A.A. Anti-microbial and anti-oxidant activities of new metal complexes derived from 3-aminocoumarin. Molecules 2011, in press.

27. Musa, A.Y.; Kadhum, A.A.H.; Mohamad, A.B.; Rahoma, A.A.B.; Mesmari, H. Electrochemical and quantum chemical calculations on 4,4-dimethyloxazolidine-2-thione as inhibitor for mild steel corrosion in hydrochloric acid. J. Mol. Struct. 2010, 969, 233-237.

Sample Availability: Samples of the compounds 1-9 are available from the authors.

(C) 2011 by the authors; licensee MDPI, Basel, Switzerland. This article is an open access article distributed under the terms and conditions of the Creative Commons Attribution license (http://creativecommons.org/licenses/by/3.0/). 